\title{
Ola Didrik Saugstad - An Oxygen Radical
}

\author{
Christian P. Speer ${ }^{a}$ Henry L. Halliday ${ }^{b}$ \\ a University Children's Hospital, University of Würzburg, Würzburg, Germany; ${ }^{b}$ Royal Maternity Hospital, Belfast, UK
}

Ola Didrik Saugstad was born in 1947 and grew up in the hills surrounding Oslo with his two sisters and brother. His father was a Professor of Psychology at the University of Oslo and his mother a high school teacher. In his younger days, football in the summer and cross-country skiing in the winter were passionate activities. Nowadays he is a dedicated runner and skier.

In 1973, after graduating as MD from the University of Oslo, he became a research fellow in Uppsala, Sweden, with Prof. Gösta Rooth (1918-2008) as his supervisor and mentor. There he developed a new method for measuring the purine metabolite hypoxanthine in small volumes of blood. He showed that hypoxanthine is elevated in blood after intrauterine hypoxia and his $\mathrm{PhD}$ thesis 'Hypoxanthine as an Indicator of Hypoxia' (1997) was based on these findings. After this he trained as an intern in the Department of Pediatrics at Ullevål University Hospital from 1979 to 1984, interrupted by a oneyear postdoctoral studentship in the Division of Perinatology/Neonatology at the University of San Diego, California, supported by a Fogarty stipend from the National Institutes of Health. In San Diego, under the tutorship of Louis Gluck and Mikko Hallman, he first became involved in surfactant research. He also pursued his ideas on reoxygenation injury caused by free radicals generated by the hypoxanthine-xanthine oxidase system. By the end of the 1970s, Ola Saugstad and co-workers believed that a burst of oxygen free radicals was produced during post-hypoxic reoxygenation and they were

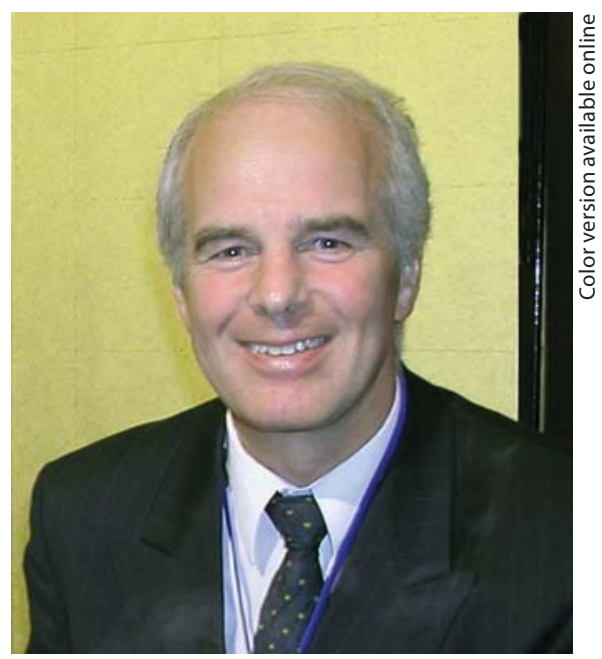

the first to publish this theory in European Surgical Research in 1980.

In 1984, he returned to the Department of Pediatrics at Rikshospitalet University Hospital in Oslo and in 1986 was appointed as Consultant Neonatologist. In 1991, he became full Professor of Pediatrics and Director of the Department of Pediatric Research at Rikshospitalet, the largest pediatric research institute in Norway. His main focus was on how oxidative stress could injure preterm infants, coining the term 'the oxygen radical disease of the newborn' in which he speculated that retinopathy of

\section{KARGER}

Fax +41613061234 E-Mail karger@karger.ch www.karger.com
(C) 2008 S. Karger AG, Basel

$1661-7800 / 08 / 0943-0188 \$ 24.50 / 0$

Accessible online at:

www.karger.com/neo
Prof. Christian P. Speer, MD, FRCPE

University Children's Hospital, University of Würzburg, Josef-Schneider-Strasse 2 DE-97080 Würzburg (Germany)

Tel. +49 931201 27831, Fax +49 93120127833

E-Mail speer_c@kinderklinik.uni-wuerzburg.de 
prematurity, bronchopulmonary dysplasia, necrotizing enterocolitis, patent ductus arteriosus and periventricular leukomalacia are different facets of one disease sharing one basic pathogenetic mechanism. The new focus on detrimental effects of oxidative stress contributed to a more careful attitude to oxygenation in premature infants. Many recent studies have demonstrated that high oxygen saturations in very preterm infants increase the risk of both retinopathy of prematurity and chronic lung problems.

In 1980, Ola Saugstad proposed that resuscitation should be carried out with as little supplemental oxygen as possible and subsequently he developed a newborn piglet model for hypoxia and reoxygenation. These experimental studies, that are still continuing, clearly showed that piglets can be resuscitated as efficiently with room air as with $100 \%$ oxygen. Later studies showed that resuscitation with $100 \%$ oxygen causes inflammation and injury in the lungs, myocardium and brain in newborn animals. In 1990, Ola Saugstad and colleagues from India conducted a clinical pilot study comparing room air resuscitation with the recommended standard of $100 \%$ oxygen. The immediate response was as good with room air as with $100 \%$ oxygen, but it was clear that a larger study was needed. Subsequently the Resair 2 Study from 6 countries and 10 centers enrolled 600 infants who were resuscitated with 21 or $100 \%$ oxygen. Once again, infants resuscitated in room air seemed to do well and in fact, there was a strong trend towards a $40 \%$ reduction in neonatal mortality in the group resuscitated with $21 \%$ oxygen. Today more than 2,000 term or near-term infants have been enrolled into 10 studies and several meta-analyses show a $30-40 \%$ reduction in neonatal mortality by substituting room air for pure oxygen during resuscitation. In strictly randomized European data the relative risk for neonatal death is lowered by almost $70 \%$ using room air (1.2\%) instead of $100 \%$ oxygen (3.9\%). These findings prompted a worldwide change in practice to lower inspired oxygen concentrations and shorten oxygen exposure in near-term and term infants in need of resuscitation, and several countries have adopted new guidelines stating that newborn resuscitation should be initiated with $21 \%$ oxygen.

Ola Saugstad's third area of interest is surfactant treatment of preterm infants with respiratory distress syn- drome. In 1985, he joined the Collaborative European Multicenter Study Group on Surfactant Replacement founded and coordinated by Bengt Robertson and Tore Curstedt from Stockholm and Henry Halliday from Belfast. Since then he has played an active part in organizing yearly scientific meetings on various aspects of basic and clinical surfactant research together with the founders of this group and Christian Speer from Würzburg.

Ola Saugstad has received a large number of honorary positions and awards throughout his impressive career, serving continuously as council and board member of various perinatal and neonatal societies and as Secretary of the Working Group on Neonatology within the European Society of Paediatric Research from 1987 to 1990 , Chairman of the Norwegian Society of Perinatal Medicine from 1987 to 1989, President of the European Association of Perinatal Medicine from 2002 to 2004. In addition, he has been President of various international and national meetings and has received the prestigious Arvo Yllpö International Award for Neonatal Medicine in 1997, the Virginia Apgar Prize in 2001 and the Human Protection Award in Norway 2007. In 1996, he was made a Fellow of the Royal College of Physicians of Edinburgh.

He has published more than 300 original articles and book chapters mainly on the topics of hypoxia and purine metabolism, hypoxia-reoxygenation injury, the effect and mechanisms of oxygen radicals in the neonatal period, mechanisms of lung injury and newborn resuscitation. Ola Didrik Saugstad is a world renowned expert in neonatal medicine and has been invited as a guest speaker at numerous international meetings in Africa, Asia, Australia, Europe and the USA. With his international connections he is one of very few European neonatologists and scientists who are highly respected in many parts of the world. Moreover, his focused and innovative research has contributed to a better understanding of the potentially harmful role of oxygen and oxygen radicals and has contributed to improved survival of high-risk preterm infants. With his modest and charming personality he has made multiple friends in basically all parts of the globe. Many of his friends have decided to take part in this year's 'Recent Advances in Neonatal Medicine' which is dedicated to Ola Didrik Saugstad. 